\title{
STUDIES ON THE PATTERN OF SELF- INCOMPATIBILITY IN RELATION TO MORPHOLOGICAL AND MOLECULAR DIVERSITY IN HAMELIA PATENS JACQ. (RUBIACEAE)
}

\author{
FILMA LOUIS ${ }^{1}$, RENJUMOL. $\mathbf{R}^{2} \&$ P. M. RADHAMANY ${ }^{3}$ \\ ${ }^{1,2}$ Department of Botany, University of Kerala, Kariyavattom \\ Thiruvananthapuram, Kerala, India \\ ${ }^{3}$ Professor, Department of Botany, University of Kerala, Kariyavattom, \\ Thiruvananthapuram, Kerala, India
}

\begin{abstract}
Genetic variation provides the foundation for species to respond to changes in the natural environment. Self fertilization is a common mating system in plants, and is known to reduce genetic diversity; increase genetic structure and potentiality put population at greater risk of extinction. Hamelia patens Jacq. is an exotic ornamental plant, widely distributed in Indian garden. Even though the plant flowers throughout the year, it never produces seeds, and hence genetic diversity is lacking in this taxon. From the previous analysis it was found that, gametophytic self-incompatibility is operating in this plant. In the present study, 14 accessions of $H$. patens were collected from different parts of Kerala and found that, accession No.3 has significant morphological differences compared to other accessions. Crossing between morphologically similar plants from various localities failed to set-seeds, whereas crosses between morphologically dissimilar plants always set-seeds. This species have both self-incompatible (on selfing) and compatible (crossing) populations, and are there for ideal for understanding how the mating system affect genetic diversity and structure. In the present study, morphologically different plant shows genetic variability which is confirmed by random amplified polymorphic DNA analysis.
\end{abstract}

KEYWORDS: Hamelia patens, Self-incompatible, RAPD, Genetic Diversity \& SRNase

Received: Apr 05, 2017; Accepted: May 02, 2017; Published: May 29, 2017; Paper Id.: IJBRJUN20173

\section{INTRODUCTION}

The majority of flowering plants produce perfect flowers that contain both the male and female reproductive organs in close proximity; consequently, they would have a strong tendency to self-fertilize, if there were no mechanisms to prevent them from doing so. To avoid the inbreeding, hermaphroditic plants have adopted a variety of reproductive strategies, including self-incompatibility (SI), by which inbreeding is prevented and outcrosses are promoted. SI allows the pistil of a flower to distinguish between genetically related (self) and unrelated (non-self) pollen. This self/non-self recognition results in the inhibition of germination of self-pollen on the stigmatic surface, or the inhibition of growth of self-pollen tubes in the style. Thus, SI is a prezygotic reproductive barrier, by which incompatible pollen/pollen tubes are prevented from delivering the sperm cells to the ovary to affect double fertilization.

Hamelia patens Jacq., commonly known as 'scarlet bush' or 'fire bush' is a large perennial shrub or small tree. Also, the plants are used in folk medicine against a range of ailments. All parts of $H$. patens are used in natural medicine. A number of active compounds have been found in fire bush, such as apigenin, ephedrine, flavanones, isomaruquine, isopteropodine, maruquine, narirutins, oxindole alkaloids, palmirine, pteropodine, rosmarinic acid, rumberine, rutin, seneciophylline, speciophylline, isopteropodine, stigmast-4-ene-3,6-dione and tannin [Cavanagh (1963), Duke (2007), 
Aquino (1990), Ahmad et al., (2012), Paniagua et al., (2012)] (-)-hameline, tetrahydroalstonine, aricine, uncarine F, stigmast-4-ene-3, 6-dione and 5,7,2-,5- -tetrahydroxyflavanone 7- rutiroside [Aquino (1990), Ahmad et a., (2012), Paniagua et al., (2012)]. The bark also contains significant amounts of tannins. Firebush contains crude protein and has in vitro digestibility [Ibrahim (1997)]. The plant possesses analgesic, antispetic, anti-inflammatory, febrifuge, refrigerant properties. Fruit of H. Patens is edible [Irobi et al., (1996) ]and the plant is used in herbal medicine to treat athlete's foot, skin lesions and rash, insect bites, nervous shock, inflammation, rheumatism, headache, asthma, and dysentery [Lachoria et al., (1999) \&Liogiery(1999)]. Ethanolic extract of different parts like leaf, stem and root of H. patens shows anthelmintic and antimicrobial activity [Sapna et al., 1996]. It has been reported to exhibit that, this plant possesses anti-diarrhoeal activity [Salud et al., 1996]. It is also used for insect bites, menstrual disorders, uterine and ovarian affliction (Shrisha et al., 2011). Cytostatic and cytotoxic activity against tumor cell lines [Taylor et al., 2013] and wound healing activity [ Sandya et al., 2011] with H. patens. Antifungal properties of aqueous extracts of leaves, flowers and fruits of Hamelia patens was also reported [Abu backer et al., 2013]. Antibacterial properties [Camporese et al., (2003), Grijalva (1992), Gupta (1995), Martinez et al., (2001)], vasorelaxant [Reyes et al., 2004] and toxicity and antinociceptive effects of Hamelia patens also studied [Castro et al., 2015]. In India, this plant is particularly cultivated on a wider scale in home gardens as an ornamental plant.

In $H$. patens, flowering and fruiting occurs throughout the year. But, it restricts the propagation to vegetative means due to the lack of seeds. Louis and Radhamany (2009) reported that, failure of sexual reproduction in H. patens is due to gametophytic incompatibility. In the present study, pattern of incompatibility in relation to morphology and total genomic variation was assessed among 14 accessions of $H$. patens.

\section{MATERIALS AND METHODS}

\section{Plant Material}

Fourteen accessions of $H$. patens viz. Acc 1, Acc 2, Acc 3, Acc 4, Acc 5, Acc 6, Acc 7, Acc 8, Acc 9, Acc 10, Acc 11, Acc 12, Acc 13 and Acc 14 collected from different parts of Kerala and maintained in the Botanical garden, Department of Botany, University of Kerala, Kariavattom were used for the present study.

\section{Morphology}

To assess the morphological diversity, twelve quantitative and twenty four qualitative characters were analysed.

\section{MOLECULAR CHARACTERIZATIONS OF VARIOUS ACCESSIONS BY RAPD MARKER ANALYSIS}

For RAPD analysis, leaves of 14 accessions of $H$. patens maintained in the Botanic garden, Department of Botany, University of Kerala were collected and thoroughly rinsed with autoclaved water. Samples of 2 to 3 gm fresh weight were wrapped in aluminum foil, frozen in liquid nitrogen and stored at $-80^{\circ} \mathrm{C}$ until DNA extraction.

\section{Isolation and Purification of DNA}

Genomic DNA was isolated and purified by cetyltrimethylammonium bromide (CTAB) method explained by Dellaporta et al., 1983, with some modifications. The DNA quality was checked in agarose gel by using $1 \%$ TE buffer, and DNA quantification was done by using a UV-VIS spectrophotometer (UV1700, Schimadzu, Japan). 


\section{Arbitrary Primers}

A total of twenty 10-mer oligo nucleotide primers (Integrated DNA Technologies, USA) were initially screened using a sample, from each of the fourteen populations. Out of them, ten primers selected for final analysis based on reproducibility, clarity of bands and minimum interspecific polymorphism are (1) 5'-TGC CGA GCT G-3' (2) 5'-GGT GAC GCA G-3’(3) 5'-GTA GAC CCG (4) 5'-CCT TGA CGC A-3’ ( 5) 5'-GGA GGG TGT T-3’ (6) 5’GGT GAA CGC T-3’(7) 5'-TGG GTC CCT C-3’' 8) 5'-GTC AGT GCG G-3' (9) 5'-ACA GCC CCC A-3’(10) 5'-GGT GCG GGA A-3’.

\section{PCR Mixture}

The total reaction volume was $25 \mu \mathrm{l}$, consisted of $2.5 \mu \mathrm{l} .10 \mathrm{X}$ reaction buffer with $\mathrm{MgCl}_{2}, 2.0 \mu \mathrm{l}$ of $10 \mathrm{mM}$ of dNTP, $2.0 \mu \mathrm{l}$ of $0.2 \mathrm{pM}$ of a single 10-mer oligonucleotide, $0.5 \mu 1$ of 0.04 unit Taqpolymerase, $14 \mu 1$ of water and $4 \mu 1$ 20ng of template DNA. All the chemicals except primers were obtained from Genei (Bangalore, India). The polymerized chain reaction was carried out in a Gradient Palm Cycler (Corbet, Australia). All programs had one initial cycle with melting at $94^{\circ} \mathrm{C}$ for $2 \mathrm{~min}$, annealing at $40^{\circ} \mathrm{C}$ for 30 seconds and extension at $72^{\circ} \mathrm{C}$ for one min followed by 40 cycles of $94^{\circ} \mathrm{C}$ for 20 seconds, annealing at $40^{\circ} \mathrm{C}$ for 30 seconds and extension at $72^{\circ} \mathrm{C}$ for $1 \mathrm{~min}$.

\section{Agarose Gel Electrophoresis and Documentation}

Agarose gel was casted in a mini model horizontal gel electrophoresis unit (SciePlas, UK) by melting agarose in 1X TE buffer $\mathrm{pH}$ 8.0. Ethidium bromide $(1 \mu \mathrm{l})$ was added to the buffer after sufficient cooling, which fluoresce DNA. Five $\mu \mathrm{l}$ of each of reaction products and molecular weight marker (Genei, Bangalore, India) were mixed with $2 \mu 1$ of $6 \mathrm{x}$ gel loading dye $(0.25 \%$ bromophenol blue and $40 \%$ sucrose in distilled water). The gel was allowed to electrophoresis, until the dye migrated up to more than half of the gel. Electric current was turned off and electrodes were removed. Gel was viewed in a UV-transluminator to detect DNA bands and photographed by gel documentation system (Alpha Innotech, USA).

\section{Data Analysis}

Relative molecular weight of polypeptide bands were calculated by comparing the resolved bands of the protein molecular weight marker, using the gel documentation software (Alpha Innotech, USA). The bands present were coded as ' 1 'and when it is absent it was designated as ' 0 '. Euclidean distance was calculated among pairs, and the dissimilarity matrix was prepared and analyzed using UPGMA (Un weighted Pair Group Method with Arithmetic average) method.

\section{Self and Infraspecific Pollinations}

Self-pollination and cross pollinations between 14 accessions were done. For self-pollination, flower buds prior to anthesis were bagged and self-pollinations were carried out on the day of anthesis. For cross pollinations, flower buds prior to anthesis were emasculated and bagged one day before anthesis. On the day of anthesis, pollen grains from one accession were transferred to another accession and reciprocal cross was also done. Each pollination was repeated using 25 flowers. Flowers were retained for observing seed-set. 


\section{RESULTS}

\section{Morphology}

Analysis of morphological characters showed variations in the quantitative as well as qualitative characters. Significant variation occurred in the plants collected from Parassala (Acc 3). Out of 14 accessions of H. patens (Figure 1), Acc 3 has remarkable morphological differences (possess dark green leaves and small flowers) compared to all other accessions (possess light green leaves and large flowers).

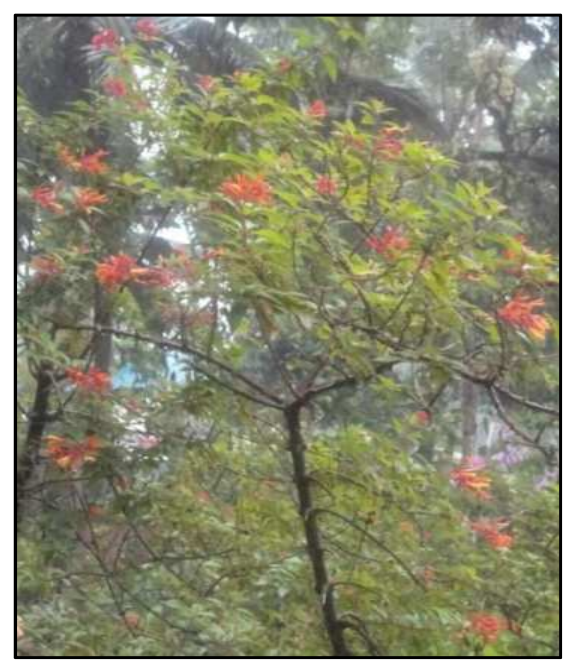

Figure 1: Habit of Hamelia Patens

The RAPD analysis has been found to be a valuable DNA marker system to evaluate genetic diversity. RAPD analysis was done using fourteen accessions of $H$. patens, collected from different parts of Kerala. Among the 20 random primers used for the initial screening, ten gave optimum RAPD profiles with all the accessions studied. Majority of the primers detected a very high level of polymorphism (Figure $2 \& 3$ ). The highest level of polymorphism explains the capability of RAPD primers to amplify the less conserved and highly repeated regions of the DNA. A total of 65 bands were generated using the ten primers chosen. The number of bands ranged from 4 to 9 per accession, when data from all the ten primers were pooled. The amplified products varied between $150 \pm 3350 \mathrm{kDa}$. 
Molecular Diversity in Hamelia Patens Jacq. (Rubiaceae)
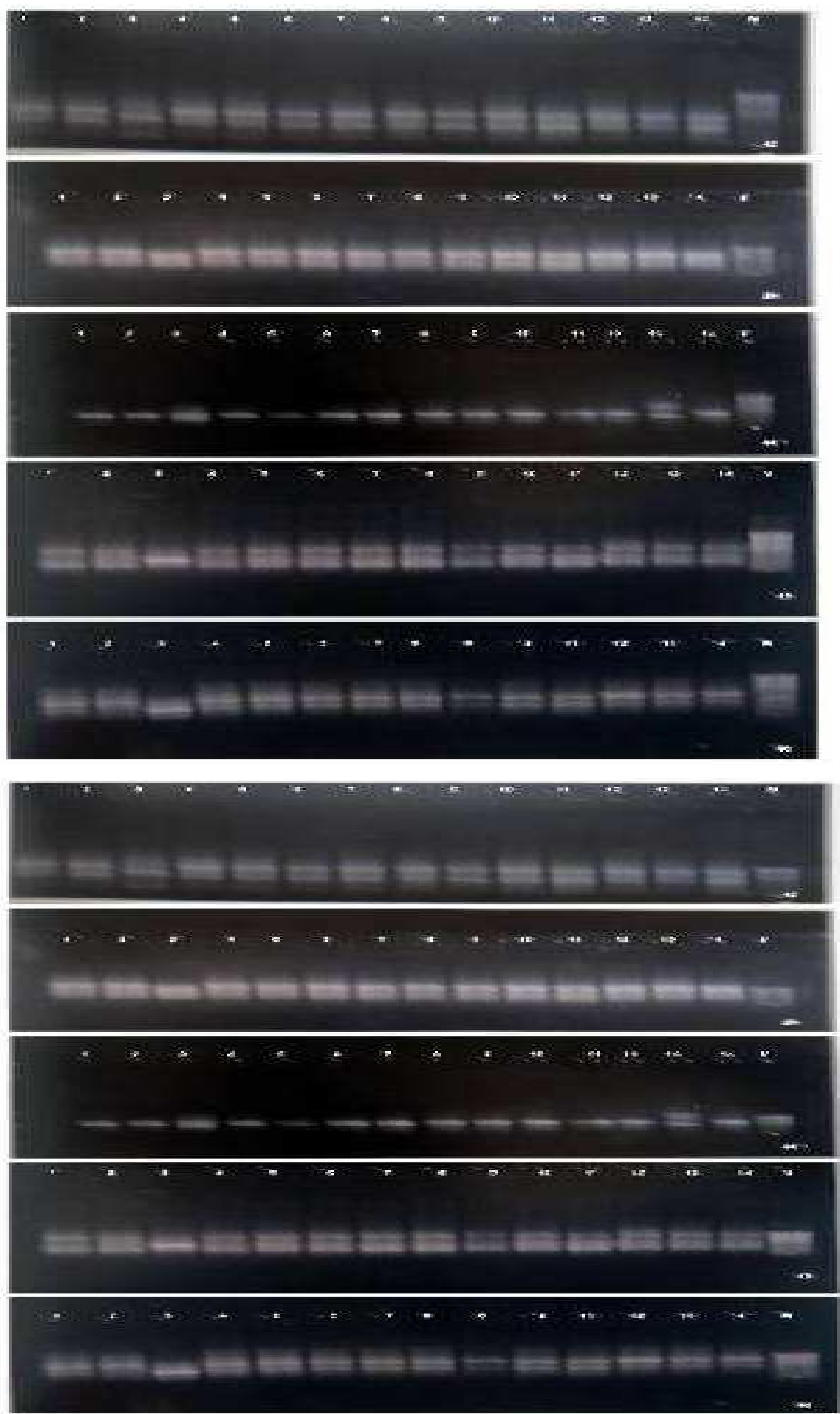

Figure 2 \& 3: RAPD Profiles of Different Accessions of Hamelia Patens

Lane1-14-Different accessions

Lane M-Marker 
The cluster of RAPD based on Euclidean distance using UPGMA method was presented in the dendrogram. It revealed two major clusters (Figure 4). The cluster I consisted of only accession (Acc 3) and cluster II consist of 13 accessions (Acc 1, Acc 2, Acc 4, Acc 5, Acc 6, Acc 7, Acc 8, Acc 9, Acc 10, Acc 11, Acc 12, Acc 13 and Acc 14.). The dendrogram showed a similar grouping based on morphology that is the morphologically similar accessions in major group and dissimilar accession (Acc3) in another.

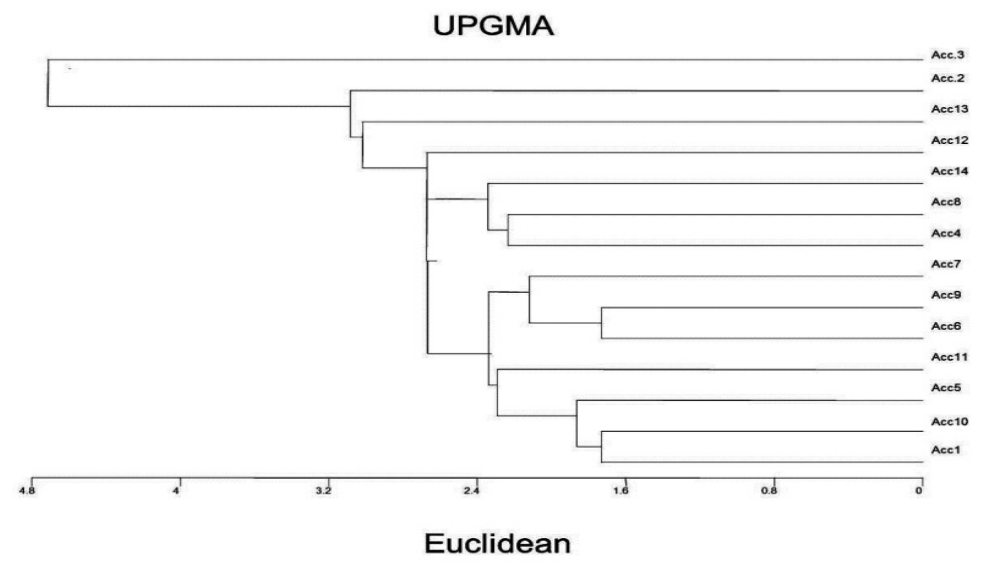

Figure 4: UPGMA Dendrogram of RAPD Analysis of 14 Accessions of Hamelia Patens

\section{SELF AND INFRASPECIFIC POLLINATIONS}

Crossing between morphologically similar plants from various localities failed to set-seeds, and these crosses were referred to as incompatible combinations. Crosses between morphologically dissimilar plants always set-seeds and these crosses were referred as compatible combinations. When Acc. 3 used as any one of the parent in the cross-pollination with other accessions, all such combination was found to be compatible. Out of 196 cross-pollinations 169 pollinations were incompatible and 27 combinations were compatible, in compatible pollinations Acc. No.3 as one of the parent (Table-1).

Table 1: Result of Self and Infraspecific Pollinations in Hamelia Patens

\begin{tabular}{|c|c|c|c|c|c|c|c|c|c|c|c|c|c|c|}
\hline Acc. No. & 1 & 2 & 3 & 4 & 5 & 6 & 7 & 8 & 9 & 10 & 11 & 12 & 13 & 14 \\
\hline 1 & - & - & - & - & - & - & - & - & - & - & - & - & - & + \\
\hline 2 & - & - & - & - & - & - & - & - & - & - & - & - & - & + \\
\hline 3 & - & - & - & - & - & - & - & - & - & - & - & - & - & + \\
\hline 4 & - & - & - & - & - & - & - & - & - & - & - & - & - & + \\
\hline 5 & - & - & - & - & - & - & - & - & - & - & - & - & - & + \\
\hline 6 & - & - & - & - & - & - & - & - & - & - & - & - & - & + \\
\hline 7 & - & - & - & - & - & - & - & - & - & - & - & - & - & + \\
\hline 8 & - & - & - & - & - & - & - & - & - & - & - & - & - & + \\
\hline 9 & & - & - & - & - & - & - & - & - & - & - & - & - & + \\
\hline 10 & - & - & - & - & - & - & - & - & - & - & - & - & - & + \\
\hline 11 & - & - & - & - & - & - & - & - & - & - & - & - & - & + \\
\hline 12 & - & - & - & - & - & - & - & - & - & - & - & - & - & + \\
\hline 13 & - & - & - & - & - & - & - & - & - & - & - & - & - & + \\
\hline 14 & + & + & + & + & + & + & + & + & + & + & + & + & + & + \\
\hline
\end{tabular}


In the case of incompatible pollinations, petals of the flowers withered away one day after pollination, but those of compatible pollinations petals persisted for 4-5 days. After one week of compatible pollinations, the ovary showed significant difference in size compared to the ovary of incompatible pollinations and mature seeds were collected after 45 days.

\section{DISCUSSION AND CONCLUSIONS}

The self-incompatibility recognition systems of angiosperms are a classical object of interest to geneticists interested in the spectacular polymorphism found in natural populations, and cell biologists interested in recognition functions. The maintenance of multiallelic polymorphism has been thoroughly investigated by classical evolutionary and population genetic approaches studied [Lawrence (1994) and Vekemans \& Slatkin (199)]. In all the species studied with homomorphic SI systems, both gametophytic and sporophytic systems, the S-loci have spectacular numbers of S-allele within the populations explained [Lane \& Lawrence (1993)]. It has long been understood that, if two different loci are involved, the self-incompatibility genes must recombine rarely or not at all, since recombination would generate genotype having the pollen type of one allele with the pistil specificity of a different allele, and these would presumably be selfcompatible.

Biochemical and molecular tools have determined the $S$-genotype of cultivars in various species. PCR based S-allele typing system could be useful for determining pollen compatibility groups of commercially important new cultivars to elucidate their incompatibility relationships. The molecular typing system of genotypes based on PCR is useful and has been used as a rapid method for indicating new S-allele and incompatibility groups in sweet cherry, in the absence of pollination tests explained (Choi et al., 2002).

RAPD and self-incompatibility (SI) typing techniques were applied to find out the genetic integrity of the two varieties of Raphanus sativus studied (Kwack et al., 2009). PCR analysis with primers designed on the conserved sequences of sweet cherry S-RNases has been used to characterize the S-genotype of 71 sweet cherry cultivars, including 26 cultivars, whose S-allele constitution had not been previously described by Wunch and Hormoza, 2004. A total of 17 pollen incompatibility groups in sweet cherry (Prunus avium L.) were identified among 46 accessions, by PCR based Sallele typing analysis and controlled test pollinations studied(Choi et al., 2002).

Field observations on the morphological features of 14 accessions of $H$. patens showed that, morphological characters are quiet consistent within 13 accessions, but accession 3 has some unique morphological features and also form compatible combination, when used as either male or female parent. Genotypic relationship based on RAPD phenotypes of the 14 accessions, with respect to the selected out groups are depicted in the phenogram generated UPGMA. The topology of the phenogram shows expected grouping with relation to the morphological and compatibility difference found among the accessions. In H. patens significant difference in the RAPD profile of Acc. 3 from other accessions may be due to its allelic difference.

The breakdown of self-incompatibility has occurred repeatedly throughout the evolution of flowering plants, and has profound impacts on the genetic structure of populations. Loss of self-incompatibility can be attributed to three types of causes: duplication of the S-locus mutations that cause loss of S-RNase activity, and mutations that do not cause loss of S-RNase activity (Dellaporta et al., 198). Duplication of the S-locus has been well studied in radiation-induced mutants, but may be a relatively rare cause of the breakdown of self-incompatibility in nature. Point mutations within the S-locus 
that disrupt the production of S-RNase have been documented in natural populations. There are also a number of mutants in which S-RNase production is unimpaired, yet self-incompatibility is disrupted. Mutations that promote self-fertility occur in both sporophytic and gametophytic SI systems and disturb S-alleles themselves as well as genes that modify S-locus expression and genes in the downstream rejection pathway described (Tsukamoto 2000, Tsukamoto 2000a, Tsukamoto 2000b, Mena - Ali \& Stephenson 2007 and Tao et al., 2007). The current models of SI maintain that the products of several unlinked genes are involved in the formation of multi-protein complex that cooperates in SI response studied by McClure and Franklin-Tong (2006). Because of the complexity of the SI response, there are many opportunities for mutations in genes involved in the rejection process to have a qualitative or quantitative effect on self-fertility studied (Good- Avila et al., 2008). Therefore, in many natural populations, SI is rather a quantitative trait due to the segregation of unlinked genes that modify the strength of SI (Levin 1996 and Good -Avila \& Stephenson 2000). The populations of the SI species with generic polymorphism for self-fertility have been found as populations in transition to SC. However, recently models with population stable state of equilibrium have been examined with mixed mating systems, where genetic polymorphism for self-fertility may modify the SI and permit selfing in the same conditions (Vallejo- Marin \& Uyenoyama 2004, Porcher \& Lande 2005a and Porcher \& Lande 2005b). The transition from SI to self-compatibility (SC) is viewed as one of the most frequent processes in plant evolution studied (Takebayashi \& Morrell 2001, Takebayashi \& Morrel 2006 and, Igic et al.,).

Louis et al., (2012) reported RNase based self incompatibility in H. patens. So, the present study concluded that, significant genetic variation with morphology and compatibility in H. patens may be due to the mutation that may disrupt the production of S-RNase. It may lead to the transition from self-incompatibility to compatibility.

\section{ACKNOWLEDGEMENTS}

We are thankful to the Head, Department of Botany, and University of Kerala for providing facilities. This research work was supported by the research fellowship from the University of Kerala, Thiruvananthapuram.

\section{REFERENCES}

1. Abubacker MN, C Sathya and R Prabakaran (2013) Invitro Antifungal potentials of Hamelia patensJacq. (Rubiaceae) Aqueous extracts of leaves, Flower and fruits. Biosciences Biotechnology Research Asia. vol, 10:2: 699-704.

2. Ahmad A, A Pandurangan, N Singh and P Ananad (2012), Aminireview on chemistryand biology of Hamelia patens (Rubiaceae). Pharmacog J. 4: 1-4.

3. Aquino R, ML Ciavatta, F De Simone and C Pizza (1990) A flavone glycoside from Hamelia patens. Phytochemistry. 29: $2359-2360$.

4. Camporese A, MJ Balick, R Arvigo, RG Esposito, NMorsellino, F De Simone and A Tubaro (2003) Screening of anti-bacterial activity of medicinal plants fromBelize (Central America). J. Ethnopharmacol. 87: 103-107.

5. Castro AJA, SB Ramos, AH Morales, JRZ Morales, MMG Chavez and CC Alvarez (2015) RevistaBrasileira de Farmacognosia, 25: 170-176.

6. Cavanagh F (1963) Analytical Microbiology, Academic Press Inc, New York.

7. Choi CR, Tao and RL Andersen (2002) Identification of self-incompatibility alleles and pollen incompatibility groups in sweet cherry by PCR based S-allele typing and controlled pollination: Euphytica. 123: 9-20.

8. Dellaporta SL, J Wooh and JB Hichs (1983) A plant DNA mini preparation: version II: Plant MolBiol Rep, 1: 19-21. 
9. Duke J (2007) Dr. Duke's Phytochemical and Ethnobotanical Databases, 19.

10. Good-Avila SV and A Stephenson (2002) The inheritance of modifiers conferring self fertility in Campanula rapunculoidesL. (Campanulaceae): Evolution, 56(56): 263-272.

11. Good-Avila SV, JI Mena-Ali and SG Stephenson (2008) Genetic and environmental causes and evolutionary consequences of variations in self-fertility in self-incompatible species. In: Self-Incompatibility in Flowering Plants - Evolution, Diversity and the Molecular Basis of Plant Genetic Diversity Mechanisms. (Franklin-Tong VE (Ed.), Springer-Verlab, Berlin, Germany). 84.

12. Grijalva A (1992) Plants utiles de la Cordllera de losMaribios. Managua, Nicaragua, Imprenta, UCA.

13. Gupta MP (1995) 270 plantasmedicinalesiberoamericanas. Santa Fe' de Bogot'Colombia:Cyted. Santa Fe' de Colombia. 27: 463-492.

14. Ibrahim MB (1997) Antimicrobial effects of extract leaf, stem and root bark of Anogeissusleio carpus on Staphylococusaureaus, Streptococcus pyrogenes, Escherichia coli and Proteus vulgaris. J. Pharma, Devpt. 2: 20-30.

15. Igic B, L Bohs and JR Kohn (2006) Ancient polymorphism reveals unidirectional breeding system shifts. ProcNatlAcadSci USA, 103: 1359-1363.

16. Irobi ON, M Young and WA Anderson (1996) Antimicrobial activity of Annatto (Bixaorellana) extract. International Journal of Pharmacy. 4: 87-90.

17. Kwak JH, S Park and MK Yoon (2009) Application of RAPD and SI-typing techniques to confirm genetic integrity of radish (RaphanussativusL.) varieties. SciHortic. 119: 352-356.

18. Lachoria L, PC Jain and SC Agarwal (1999) Activity of some plant extracts against dermatophytes. Hindustan Antibiot. Bull. 41: $17-21$.

19. Lane MD and MJ Lawrence (1993) The population genetics of the self incompatibility polymorphism in Papaverrhoeas. VII. The number of S-alleles in the species. Heredity.71: 596-602.

20. Lawrence MI and VE Franklin-Tong (1994) The population genetics of the self-incompatibility polymorphism in Papaverrhoeas IX. Evidence of an extra effect of selection acting on the S-locus. Heredity, 72: 353-364.

21. Lawrence MJ, S O'Donnell, MD Lane and DF Marshall (1994) The population genetics of the self-incompatibility polymorphism in Papaverrhoeas. VIII. Sampling effects as a possible cause of unequal allele frequencies. Heredity,72: 345 352.

22. Levin DA (1996) The evolutionary significance of pseudo-self-incompatibility. Am Nat,148:321-332.

23. Liogier HA (1999) Plantasmedicinales de Puerto Rico y delCaribe. Iberoamericana de Ediciones, Inc. San Juan, PR. 566.

24. Louis CF and PM Radhamany (2009) Pollen-pistil interactions in Hamelia patens Jacq.(Rubiaceae). J Indian Bot Soc. 88: $92-$ 97.

25. Louis CF, RSN Raj and PM Radhamany (2012) Identification and characterisation of incompatibility factors in Hamelia patensJacq.(Rubiaceae). J HorticSci\&Biotech, 87: 531-538.

26. Martinez M, RE Oliva, M Mendoza, G Morales, G Toledo and A Wrong (2001) Calalogo de plantasutiles de la Sierra Norte de Puebla, Mexico. Cuadernos 27. Mexico, D.F. Mexico: Instituto de biologia, Universidad NacionalAutonoma de Mexico,176.

27. McClure B and V Franklin-Tong (2006) Gametophyticself-incompatibility:understanding the cellular mechanisms involved in "self" pollen tube inhibition. Planta, 224: 233-245.

28. Mena-Ali JI and AG Stephenson (2007) Segregation analyses of partial self-incompatibility in self and cross progeny of 
Solanumcarolinensereveal a leaky S-allele. Genetics,177: 501-510.

29. Paniagua-Vega D, CM Cerda-García-Rojas, T Ponce-Noyola and AC Ramos-Valdivia (2012) A new monoterpenoidoxindole alkaloid from Hamelia patens micropropagated plantlets. Nat. Prod. Commun. 7: 1441-1444.

30. Porcher $E$ and $R$ Lande (2005a) The evolution of self-fertilization and inbreeding depression under pollen discounting and pollen limitation.JEvolBiol,18: 497-508.

31. Porcher $E$ and $R$ Lande (2005b) Loss of gametophytic self-incompatibility with the evolution of inbreeding depression. Evolution,59: 46-60.

32. Reyes-Chilpa R, J Rivera, M Oropeza, P Mendoza, B Amekraz, C Jankowski and M Campos (2004) Methanol extracts of Hamelia patens containing oxindolealkaloidsrelaxKCl-induced contraction in rat myometrium. Biol. Pharm. Bull. 27: 16171620.

33. Salud PG, A Miguel, S Zavala, S Rosario Vargas, Z Edgar Hernandez, M Rosa and G Perez (1996) Antidiarrhocal activity of Hamelia patens Methanol extract in rats and mice. Phytotherapy Research. 10: 686-688.

34. Sandhya S, P SaiKumar, KR Vinod, B David and K Kumar (2011) Plants as potent antidiabetic and wound healing agents - A review. Hygeia J. D. Med. 3: 11-19.

35. Sapana K, S Parul, S Tribhuwan and V Rekha (2012) Anthelmintic and antimicrobial activity of Hamelia patens Jacq.(Rubiaceae). International Journal of Natural Products Research. 1: 54-56.

36. Shrisha DL, KA Raveesha and Nagabhushan (2011) Bioprospecting of selected medicinal plants for antibacterial activity against some pathogenic bacteria. Journal of Medicinal Plants Research. 5: 4087-4093.

37. Takebayashi N and PL Morrell (2001) Is self-fertilization an evolutionary dead end? Revisiting an old hypothesis with genetic theories and a macro evolutionary approach. Am J Bot, 88 : 1143-1150.

38. Tao R, A Watari, T Hanada, T Habu, H Yaegaki, M Yamaguchi and H Yamane (2007) Self-compatible peach (Prunuspersica) has mutant versions of the Shaplotypes found in self-incompatible Prunusspecies. Plant Mole Biol. 63: 109-123.

39. Taylor P, M Arsenak, MJ Abad, A Fernandez, B Milano, R Gonto, MC Ruiz, S Fraile, S Taylor, O Estrada and F Michelangeli (2013) Screening of Venezuelan medicinal plant extracts for cytostatic and cytotoxic activity against Tumor cell lines. Phytotherapy Research. 27: 530-539.

40. Tsukamoto $T$ (1999) Breakdown of self-incompatibility in a natural population ofPetuniaaxillaris(Solanaceae) in Uruguay containing both self-incompatible and self-compatible plants. Sex Plant Repro. 12:1: 6-13.

41. Tsukamoto T (2000a) Breakdown of self-incompatibility in a natural population of Petunia axillariscaused by loss of pollen function. Plant Physiol. 131:4: 1903-1912.

42. Tsukamoto $T$ (2000b) Breakdown of self-incompatibility in a natural population ofPetuniaaxillariscaused by a modifier locus that suppresses the expression of The Molecular Basis of Plant Genetic Diversity 88RNase gene. Sex Plant Repro. 15: 5: 255263.

43. Vallejo-MarínM and MK Uyenoyama (2004) On the evolutionary costs of self-incompatibility: Incomplete reproductive compensation due to pollen limitation. Evolution,58: 1924-1935.

44. Vekemans $X$ and M Slatkin (1994) Gene and allelic genealogies at gametophytic self-incompatibility locus. Genetics,137: 1157-1165.

45. Wunsch A and JI Hormaza (2004) S-allele identification by PCR analysis in sweet cherry cultivarsPlant Breed,123:4:327-331. 